\title{
Weed control effect of unmanned aerial vehicle (UAV) application in wheat field
}

\author{
Yin Chen ${ }^{1,2,3 \#}$, Haoliang Qi ${ }^{2 \#}$, Guangze $\mathrm{Li}^{1^{*}}$, Yubin $\operatorname{Lan}^{3 *}$ \\ (1. Shenzhen Noposion Agrochemicals Co., Ltd., Shenzhen 518102, China; \\ 2. Shenzhen Yuyan Intelligent Technology Services Co. Ltd., Shenzhen 518102, China; \\ 3. National Center for International Collaboration Research on Precision Agricultural Aviation Pesticides Spraying Technology (NPAAC), \\ College of Engineering, South China Agricultural University, Guangzhou 510642, China)
}

\begin{abstract}
Wheat is a major food source throughout the world. However, biological factors like pests and weeds can lead to lower crop yield. Most crop protection nowadays involves pesticide and herbicides application. This is commonly conducted with knapsack in China, which is inefficient and high labor intensive. Unmanned aerial vehicle (UAV) are an aerial spraying technology recently-developed. Using UAV application is more flexible and standardized, the spraying efficiency is 60 times more than knapsack sprayer. However, weed management using UAV is still a challenge. Low spray volume and droplet density with less penetration may affect weed control efficacy. High droplet concentration may induce crop injury. This study focused on discovering crop safety and weed control efficacy of UAV in wheat fields. Different herbicides, rates and spray volume were tested for pre-emergence (PRE) and post-emergence (POST). The results show that no crop injury was induced for PRE. While 10\%-20\% injury on wheat was found for POST. All herbicides treatments showed significant effects on weed management compared to untreated control. However, the efficacy was not stable between years and fields. Weed management for PRE can reach $98 \%-100 \%$ when the soil is humid, smooth and with no straw coverage when using diflufenican + isoproturon $\left(120+1200 \mathrm{~g}_{\mathrm{ai} \mathrm{h}} \mathrm{ha}^{-1}\right)$. For POST application via UAV, weed injury ranged from $10 \%$ injury to $70 \%$, in which isoproturon + clodinafop-propargyl + mesosulfuron $\left(120+7.5+0.9 \mathrm{~g}_{\text {ai }} \mathrm{ha}^{-1}\right)$ injured weed the most in 2018 (reached 70\%). Knapsack sprayer showed relatively better weed control efficacy in many cases for POST applications. Weeds showed certain degree of resistance. In general, PRE application with UAV showed better potential, but herbicide spraying needs to be combined with field management to achieve better weed management efficacy.
\end{abstract}

Keywords: unmanned aerial vehicle (UAV), herbicide application, weed management, wheat DOI: $10.33440 /$ j.ijpaa.20190202.45.

Citation: Chen Y, Qi H L, Li G Z, Lan Y B. Weed control effect of unmanned aerial vehicle (UAV) application in wheat field. Int J Precis Agric Aviat, 2019; 2(2): 25-31.

\section{Introduction}

Wheat (Triticum aestivum L.) is one of the most important grain crops throughout the world especially for North America, Asia and Europe ${ }^{[1-3]}$. It provides food for about $40 \%$ of the population all over the world ${ }^{[3]}$. The human population has increased dramatically and will reach about 10 billion by $2050^{[4]}$, this will increase the need of intensive agriculture. Crop protection with pesticides and herbicides is an important step to ensure crop production in modern agriculture system ${ }^{[5]}$. It has been reported that agrochemical may enhance food supply by up to $45 \%{ }^{[6]}$. Traditional herbicide or pesticide application is normally conducted by tractor and knapsack sprayer in many area in China ${ }^{[7]}$. The disadvantages of those application methods include low efficiency (especially for knapsack sprayer), high labor intensity, time-consuming, and water consuming (225-450 L ha $\left.{ }^{-1}\right)$.

Received date: 2019-11-15 Accept date: 2019-12-15

Biographies: Yin Chen, Post-doctoral, research interests: weed science, Email: cleary@163.com; Haoliang Qi, Master, Agronomist, research interests: weed science, Email: 21260@noposion.com.

* Corresponding author: Guangze Li, PhD, Senior agronomist, research interests: agricultural industry chain, Email: 4459@noposion.com; Yubin Lan, PhD, Distinguished Professor, Director, research interests: precision agricultural aviation application, Email: ylan@scau.edu.cn.

\# these authors contributed equally to this work.
Nonstandard spraying via backward equipment results in uneven droplet distribution and waste of agrochemical ${ }^{[8]}$. In order to increase efficiency, standardize pesticide spraying, and adapt to labor decrease in rural area, modern agriculture includes agricultural aerial spraying has been developing fast during the last decades. Agricultural aerial spraying includes manned and unmanned aircraft ${ }^{[9]}$. Unmanned aerial vehicle (UAV) is more suitable for small farming plots ${ }^{[10]}$. It has been already commonly used in Japan and Korea ${ }^{[11,12]}$. UAV spraying are more flexible and standardized than conventional methods, with 60 time higher efficiency than traditional methods ${ }^{[13]}$. It causes almost none damage to crops or soil structure during operation ${ }^{[14]}$, has low labor and water cost.

Due to all the advantages, many studies have been conducted on UAV application for pesticide includes insecticide and fungicide. Those studies promoted the usage of UAV on crop protection successfully, the techniques of UAV spraying have been developing ${ }^{[15-17]}$. However, herbicide application via UAV has always been a challenge. UAV spraying is followed with low spray volume and limited droplet distribution due to limited battery endurance and small loading capacity ${ }^{[18]}$. Droplet concentration will increase when spray volume decrease. Droplet concentration for UAV spraying may be 30 times more than that of traditional spray methods. High droplet concentration of some herbicides may induce crop injury. Many studies reported that droplet size, 
droplet concentration, spray volume affect herbicide application efficacy ${ }^{[19]}$. When droplet concentration is high, uptake of to increased herbicide gradient. Some studies showed that low spray volume may decreased some herbicides' efficacy ${ }^{[20]}$ while it has opposite effect on some other herbicides ${ }^{[21,22]}$. In addition, proper adjuvant increases weed management efficacy via increasing adsorption and decrease evaporation and dripping ${ }^{[23,24]}$. Therefore, herbicide applied by UAV is possible but the efficacy may vary a lot among spray parameters and herbicides. For herbicide application via UAVs, drift risk is also a problem due to high spray height. Therefore, the requirement for herbicide selection will be more strict. Because of those challenges, progress about herbicide application via UAVs is very limited. The information about weed management via UAV spraying in wheat field is still lacking. More experiments should be conducted to discover the possibility of herbicide application via UAV.

The purpose of this study was to explore the potential of UAV to conduct herbicide application tasks in wheat fields. To find out the appropriate herbicides for weed management in wheat fields for herbicide may decrease due to leaf tissue necrosis or increase due

UAV application and to test how application affects crop safety, weed management efficacy.

\section{Materials and methods}

\subsection{Field experiments}

Experiments were conducted in wheat fields in Jiangsu province, China from the winter of 2017 to spring 2018, and repeated from winter of 2018 to spring 2019. Soil in the experiment area contains $4.1 \%-5.8 \%$ organic matter and has a $\mathrm{pH}$ of 6-6.5. Field was plowed to mix straw from last rice season with soil and was disked to create a relatively smooth surface. Some of the soil surface was still covered with straw when the experiments were conducted (Figure 1). Seeds were sown in drill and most of them were 0 to $3 \mathrm{~cm}$ below soil surface. Seed line spacing was about $10 \mathrm{~cm}$. Fields were not irrigated after sowing and before reviving stage. Management practices included pest control, fertilization and irrigation (at or after reviving stage) were conducted to optimize crop growth. Experimental design used randomized complete block. Each UAV treatment area was between 0.13 to 0.25 ha for all the experiments.
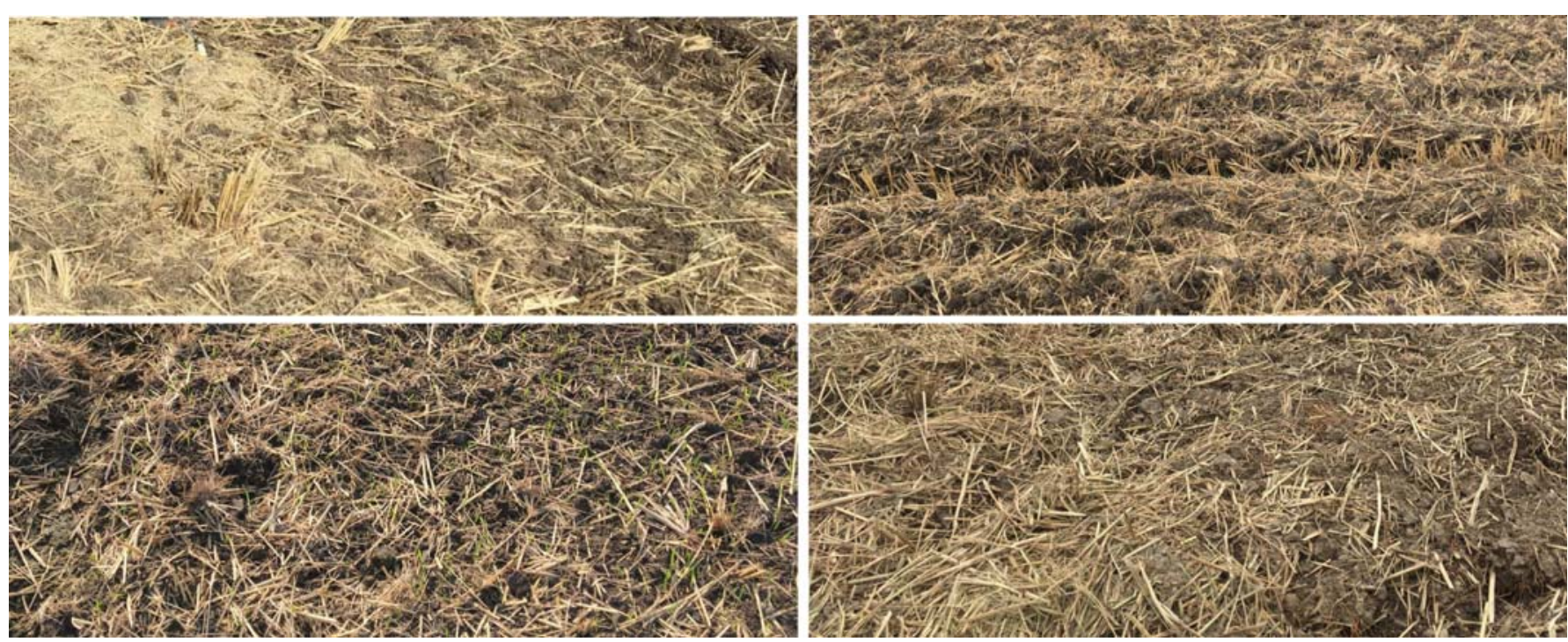

Figure 1 Soil surface before herbicide application

Both pre-emergence (PRE) and post-emergence (POST) applications were conducted. PRE applications were operated after seed sowing to control ungerminated or newly germinated weeds. Two herbicide combinations, two application time (5 or 20 days after sowing), two herbicide rate were tested (Table 1 ). Low rate (20\% less than rate commonly used in the experimental area) was tested in the same area only in 2018 to explore the possibility of herbicide reduction. POST application was taken after reviving stage before wheat jointing stage depending on weed growth. Two herbicides combinations and two rate were tested in 2018 (Table 2-1). Three herbicide combinations with one rate and two spray volume were tested in 2019 (Table 2-2). For each field, two untreated (no herbicide applied) areas about 0.05 ha were used as control (CK).

Table 1 Experimental design for PRE treatments in 2017 and 2018 winter

\begin{tabular}{|c|c|c|c|c|}
\hline Application method & Herbicides & Application time (d after seeding) & Rate/g ai $\cdot \mathrm{hm}^{-2}$ & Spray volume $/ \mathrm{L} \cdot \mathrm{hm}^{-2}$ \\
\hline \multirow{4}{*}{ UAV } & \multirow{3}{*}{ Diflufenican + isoproturon } & 5 & $180+1800$ & \multirow{4}{*}{18.75} \\
\hline & & 5 & \multirow{2}{*}{$120+1200^{\mathrm{a}}$} & \\
\hline & & 20 & & \\
\hline & Flufenacet + diflufenican +flurtamone & 5 & $165+165+165$ & \\
\hline \multirow{4}{*}{ Knapsack sprayer } & \multirow{3}{*}{ Diflufenican + isoproturon } & 5 & $180+1800$ & \multirow{4}{*}{450} \\
\hline & & 5 & \multirow{2}{*}{$120+1200^{\mathrm{a}}$} & \\
\hline & & 20 & & \\
\hline & Flufenacet + diflufenican +flurtamone & 5 & $165+165+165$ & \\
\hline
\end{tabular}

Note: ${ }^{\text {a }}$ Rate of $120+1200 \mathrm{~g}$ ai hm ${ }^{-2}$ was only tested in 2018 . 
Table 2-1 Experimental design for POST treatments in 2018 spring

\begin{tabular}{|c|c|c|c|}
\hline Application method & Herbicides & Rate/g ai $\cdot \mathrm{hm}^{-2}$ & Spray volume $/ \mathrm{L} \cdot \mathrm{hm}^{-2}$ \\
\hline \multirow{4}{*}{ UAV } & \multirow{2}{*}{ Isoproturon + clodinafop-propargyl + mesosulfuron } & $120+7.5+0.9$ & \multirow{4}{*}{18.75} \\
\hline & & $80+5+0.6$ & \\
\hline & \multirow{2}{*}{ Isoproturon + clodinafop-propargyl + flucarbazone-sodium } & $120+7.5+4.5$ & \\
\hline & & $80+5+3$ & \\
\hline Knapsack sprayer & Isoproturon + clodinafop-propargyl + mesosulfuron & $120+7.5+0.9$ & 225 \\
\hline
\end{tabular}

Table 2-2 Experimental design for POST treatments in 2019 spring

\begin{tabular}{|c|c|c|c|}
\hline Application method & Herbicides & Rate/g ai $\cdot \mathrm{hm}^{-2}$ & Spray volume $/ \mathrm{L} \cdot \mathrm{hm}^{-2}$ \\
\hline \multirow{6}{*}{ UAV } & \multirow{2}{*}{ Isoproturon + mesosulfuron + florasulam } & \multirow{2}{*}{$120+0.9+0.7$} & 15 \\
\hline & & & 22.5 \\
\hline & \multirow{2}{*}{ Pinoxaden + clodinafop-propargyl + florasulam } & \multirow{2}{*}{$7.5+7.5+1$} & 15 \\
\hline & & & 22.5 \\
\hline & \multirow{2}{*}{ Flucarbazone-sodium + clodinafop-propargyl + mesosulfuron + florasulam } & \multirow{2}{*}{$3.2+7.5+0.9+1$} & 15 \\
\hline & & & 22.5 \\
\hline \multirow{3}{*}{ Knapsack sprayer } & Isoproturon + mesosulfuron + florasulama & $120+0.9+0.7$ & \multirow{3}{*}{225} \\
\hline & Pinoxaden + clodinafop-propargyl + florasulama & $7.5+7.5+1$ & \\
\hline & Flucarbazone-sodium + clodinafop-propargyl + mesosulfuron + florasulama & $3.2+7.5+0.9+1$ & \\
\hline
\end{tabular}

The guideline of precautions for application was followed strictly: temperature was not lower than $0^{\circ} \mathrm{C}$ before, during and 7 days after application. Heavy rainfall and impounded surface water within 7 days after application should be avoided. Herbicide applications were conducted between 9 am $11 \mathrm{am}$. No precipitation occurred at least 12 hours prior to or after application. In some PRE experiments, precipitation occurred 2-3 days after application, which may help herbicides settling in soil. Experiments used DJI MG-1S and 1P (DJI, Shenzhen, China, 518057) for UAV treatments. XR1101VS (TeeJet Technologies (Tianjin) Co. Ltd., Tianjin, China, 300385) nozzles were equipped on UAV when applying herbicides. Knapsack sprayer was from local farming store and equipped with cone nozzle. The fixed flight parameters for the experiment include flight height $1.5 \mathrm{~m}$, spray amplitude $3.5 \mathrm{~m}$, flight speed $4.5 \mathrm{~m} \mathrm{~s}^{-1}$. The optimal flight parameters used in herbicides experiments were from previously UAV tests (data unpublished).

\subsection{Statistical analysis}

Crop tolerance was evaluated visually 7 and 14 DAT using a scale of 0 to $100(0=$ no damage, $100=$ plant death $)$. Injury symptoms were evaluated, which included stunting, bleaching on leaves and tissue necrosis. Weed control efficacy was evaluated from 7 to 30 DAT. For PRE application experiments, weed number was counted. For POST applications, only weed injury level was recorded. PROC GLM (SAS 9.3, SAS Institute Inc., 100 SAS Campus Drive, Cary, NC 27513) was used for data analysis. Means were compared using Student-Newman-Keuls test $(\alpha=0.05)$.

\section{Results and discussion}

\subsection{Sensitivity of wheat to selected herbicides applied with UAV}

When following the guideline of precautions for application UAV application of diflufenican + isoproturondid or flufenacet + diflufenican + flurtamonenot did not induce wheat seed or seedling injury when applied 5 or 20 days after seeding in 2017 and 2018 winter. Herbicides and rates used in this study were safe to wheat before and after seed germination when applied PRE via UAV. For POST treatments, wheat seedlings expressed about 10\%-15\% injury after isoproturon + clodinafop-propargyl + mesosulfuron $\left(80+5+0.6 \mathrm{~g} \mathrm{ai} \mathrm{hm}^{-2}\right)$ treatments in 2018 spring. Injury increased to about $20 \%$ when the rate was $120+7.5+0.9 \mathrm{~g}$ ai hm $\mathrm{hm}^{-2}$. The main symptom of the seedlings is whole plant chlorosis (Figure 2). Seedlings were fully recovered about 20 days after treatment (DAT) and wheat growth was not affected according to observation. Isoproturon + clodinafop-propargyl + flucarbazone-sodium treatments with both equipments and isoproturon + clodinafoppropargyl + mesosulfuron applied with knapsack sprayer did not induce any injury. This indicates that for this herbicide combination with mesosulfuron, spray volume may affect crop safety. Using more water during application may increase the safety. POST treatments in 2019 did not induce wheat injury. However, if UAV was resprayed (hovering above the same area when spraying), it may induce severe injury to wheat seedlings. This should be avoided during herbicide application. The results indicate that UAV application of herbicides on wheat is possible and relatively safe. However, even when the herbicide combination and rate is safe for wheat seedling in this study. UAV application may still injure wheat seedlings due to sensitive wheat varieties or environment ${ }^{[25]}$. Every herbicide application with UAVs should be tested in a small area before large-scale application.

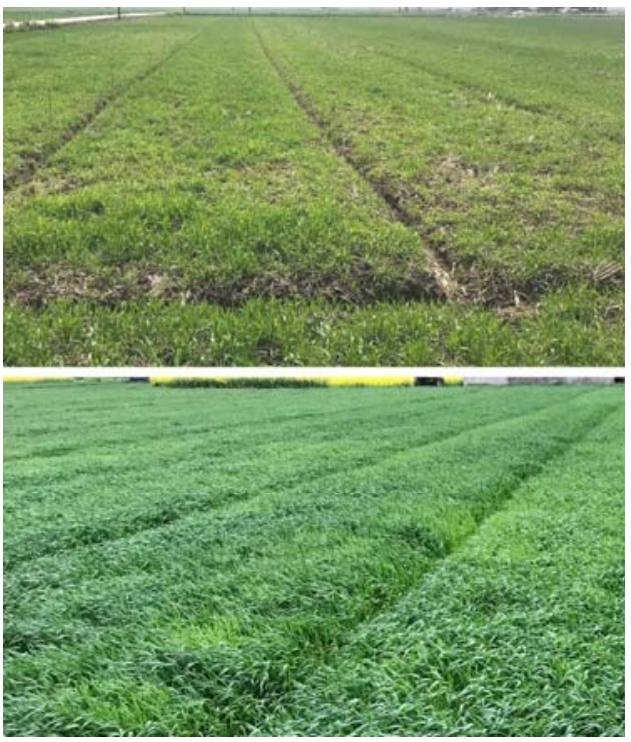

Figure 2 Response of wheat seedlings to UAV POST application of isoproturon + clodinafop-propargyl + mesosulfuron $(120+7.5+$ $0.9 \mathrm{~g} \mathrm{ai} \mathrm{hm}^{-2}$ ) treatments in 2018 spring 12 (on) and 20 (under) days after treatment (DAT) 
3.2 Response of weeds to selected herbicides applied with UAV

\subsubsection{Response of weeds to PRE herbicide application}

All PRE herbicides applied by UAV and knapsack sprayer showed significant effects on weed management compared to untreated control (CK). However, the effect was not uniform among different fields, equipments and years. In 2017, both experiment fields had about 100-110 Japanese foxtail (Alopecurus japonicus Steud.) seedlings germinated on CK area. It was the major weed species in the wheat fields (Figure 3). In field A, about $27 \%$ less Japanese foxtail seedlings was observed in UAV application area after treated with diflufenican + isoproturon $(180+$ $1800 \mathrm{~g}$ ai hm$^{-2}$ ) compared to CK. While knapsack sprayer treatments controlled 64\% Japanese foxtail. In this field, knapsack sprayer's weed control efficacy was significantly better than UAV. In field

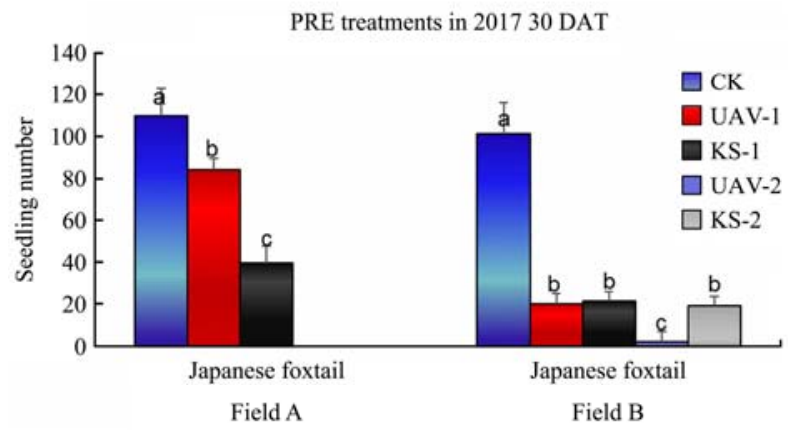

B, when diflufenican + isoproturon was applied, both UAV and knapsack sprayer application suppressed about $80 \%$ of Japanese foxtail germination. When use flufenacet + diflufenican + flurtamone, UAV application area had the least Japanese foxtail seedling number (about 5 weeds per $0.5 \mathrm{~m}^{2}$ ), which is $95 \%$ less than CK. While knapsack sprayer treatment area had about 20 weeds per $0.5 \mathrm{~m}^{2}$, which is $80 \%$ less than CK. The difference of weed management efficacy between UAV and knapsack sprayer was significant on field A but was not significant on field B. This may be because of the field quality. The soil was more humid in field $\mathrm{B}$ because there are irrigation channels around the plot. In addition, there is less straw covering the soil surface, and the soil is relatively smooth and fine for field B. Herbicides are more likely to form a herbicide coverage on soil surface relying on soil moisture, and therefore is less affected by low spray volume of UAV.

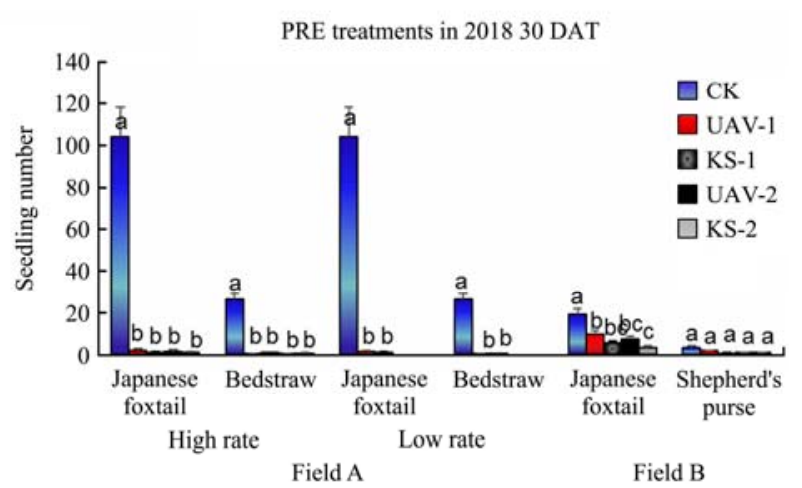

Note: CK, UAV-1, KS-1, UAV-2, KS-2 represent untreated control, diflufenican + isoproturon (high rate: $180+1800 \mathrm{~g}^{2} \mathrm{hm} \mathrm{hm}^{-2}$ or low rate $120+1200 \mathrm{~g}$ ai hm ${ }^{-2}$ ) applied with UAV and applied with knapsack sprayer, flufenacet + diflufenican +flurtamone $\left(165+165+165\right.$ g ai hm $\left.{ }^{-2}\right)$ applied with UAV and applied with knapsack sprayer. In 2018, low rate (20\% less than high rate) treatments were added in field A. Data were taken 30 days after treatment (DAT). Vertical bars represent standard error. Means with the same letter within the same field, herbicide rate and weed species are not significantly different according to Student-Newman-Keuls $(\alpha=0.05)$.

Figure 3 Response of major species weeds (showed as germinated seedling number per $0.5 \mathrm{~m}^{2}$ ) to PRE herbicides applied with different equipment 30 days after treatment (DAT)

In 2018 winter, UAV application of diflufenican + isoproturon showed great weed management effect (suppressed more than $98 \%$ of the weeds) on Japanese foxtail and bedstraw (Galium aparine L.) (two major weed species) on field A (Figure 3). More than 100 Japanese foxtail seedlings and 25 bedstraw seedlings were observed for CK area, while only about 0-2 weeds were observed per $0.5 \mathrm{~m}^{2}$ for treated area. Most of the treated area had no weed seedling (Figure 4). No significant difference on weed management effect was observed between different herbicide rate (diflufenican + isoproturon of $180+1800 \mathrm{~g}$ ai hm $\mathrm{hm}^{-2}$ and $120+$ $1200 \mathrm{~g}$ ai hm${ }^{-2}$ ), between UAV and knapsack sprayer and between different herbicide combinations (diflufenican + isoproturon and flufenacet + diflufenican +flurtamone) on field A. For field B, Japanese foxtail and shepherd's purse (Capsella bursa-pastoris) were major weed species. About 20 Japanese foxtail and 4 shepherd's purse seedlings were observed per $0.5 \mathrm{~m}^{2}$ in CK area (Figure 3). UAV application of diflufenican + isoproturon decreased about $60 \%$ Japanese foxtail seedlings and 50\% shepherd's purse respectively. While knapsack sprayer application of diflufenican + isoproturon controlled about $75 \%$ Japanese foxtail and $80 \%$ shepherd's purse respectively. UAV application of flufenacet + diflufenican +flurtamone controlled $70 \%$ Japanese foxtail and $80 \%$ shepherd's purse while knapsack sprayer application decreased about 85\% Japanese foxtail and $80 \%$ shepherd's purse. However, the difference is not statistically significant. As showed in the Figure 2, weed management effect on field A in 2018 is much better than any other fields of 2017 and 2018. Even when the rate was $20 \%$ less than commonly used rate, weed management effect was not affected. It is because there was no straw exist on this field and the soil surface was smooth (Figure 4). Besides, the weather in 2018 winter was more humid than 2017 and more rainfall there was in 2018 winter. As mentioned above, soil moisture help PRE herbicide to form a herbicide film on soil surface. Especially when spray volume is too low to provide enough moisture. Big soil particles and straws on soil surface can both prevent the formation of herbicide film. Therefore, using UAV to apply PRE herbicide has great potential, but it need a correlated soil management technique to achieve great weed management performance. In addition, PRE herbicide is able to suppress many weed species that are resistant to POST herbicides because POST herbicide resistance occurs more frequent and faster than $\mathrm{PRE}^{[26]}$. Therefore, it is meaningful to conduct more researches about PRE herbicide application via UAVs.

3.2.2 Response of weeds to POST herbicide application

For POST application, all treatments induced significant weed injury compared to untreated control (CK). However, the weed control effect has great difference among treatments, fields and years, ranged from $10 \%$ injury to $80 \%$. In addition, weed species of this area showed certain level of resistance for the herbicides selected. In 2018, Japanese foxtail was the major weed species. No significant difference was detected between UAV and knapsack sprayer, herbicide combinations, and herbicide ratefor weed control effect (Figure 5). On field A, UAV application of isoproturon + clodinafop-propargyl + mesosulfuron of low and high rate herbicides induced approximate 68 and $72 \%$ injury respectively, 
while knapsack sprayer induced $80 \%$. On field B, UAV application with lower rate of herbicide combinations induced in

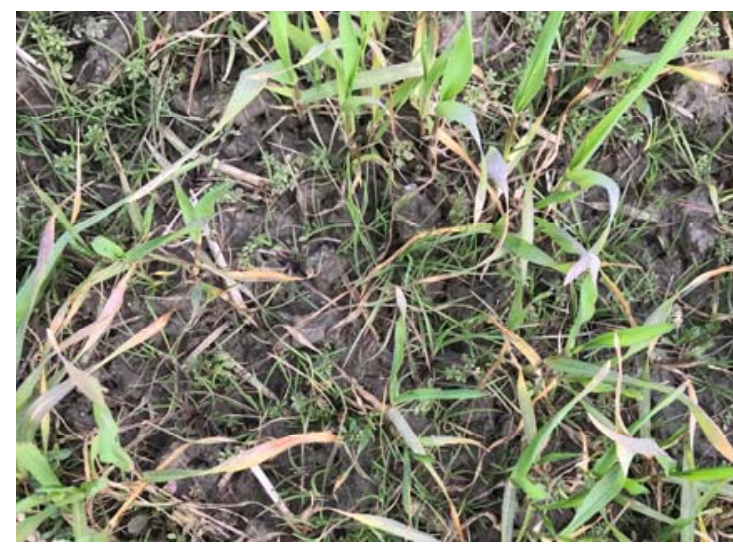

CK average $48 \%-50 \%$ injury on Japanese foxtail and higher rate was $62 \%-65 \%$. knapsack sprayer was $68 \%$.

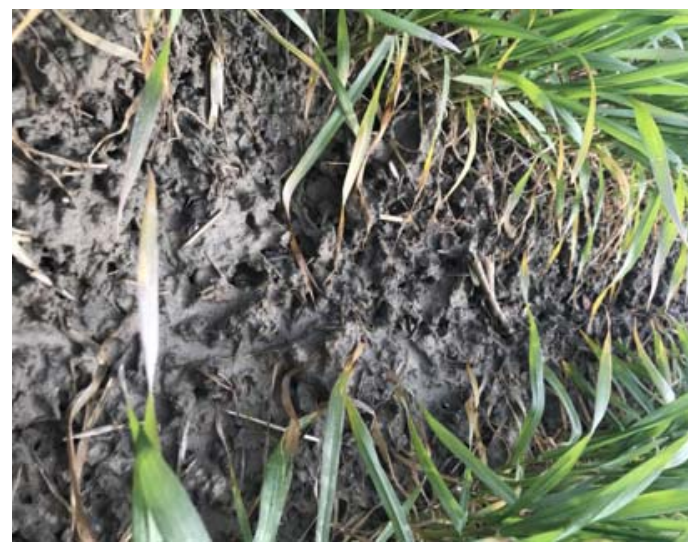

PRE treatment

Figure 4 Response of weeds to UAV PRE application of diflufenican + isoproturon $\left(120+1200 \mathrm{~g} \mathrm{ai} \mathrm{hm}^{-2}\right) 30$ days after treatment (DAT)
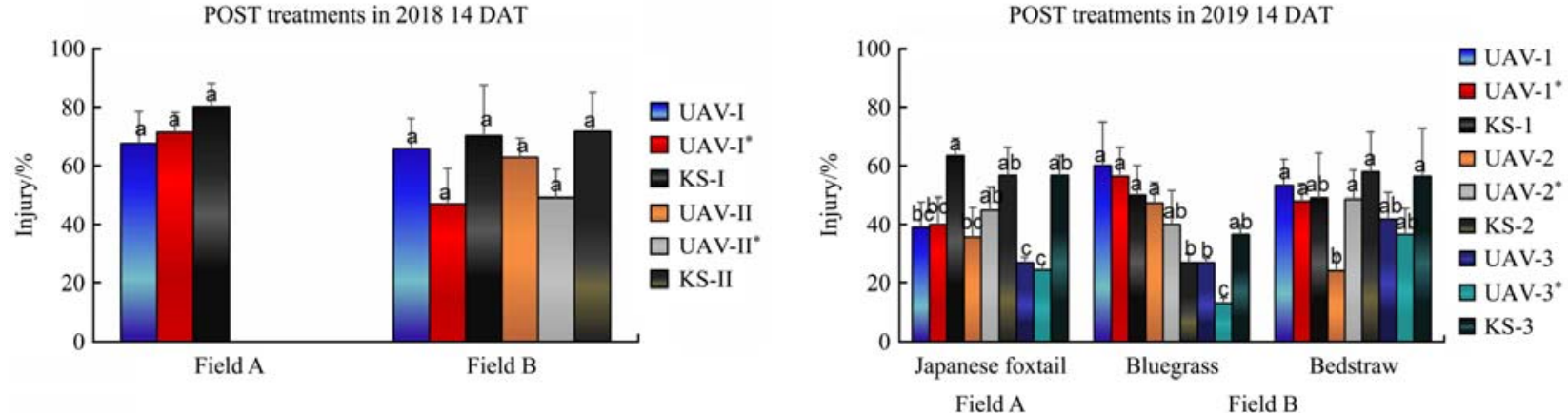

Note: For data from 2018, UAV-I, UAV-I*, KS-I represent UAV application of isoproturon + clodinafop-propargyl + mesosulfuron with high (120 + $7.5+$

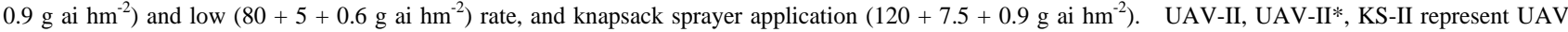
application of Isoproturon + clodinafop-propargyl + flucarbazone-sodium with high $\left(120+7.5+4.5 \mathrm{~g}\right.$ ai hm $\left.\mathrm{hm}^{-2}\right)$ and low $\left(80+5+3 \mathrm{~g}\right.$ ai hm $\left.{ }^{-2}\right)$ rate, and knapsack sprayer application $\left(120+7.5+4.5 \mathrm{~g}\right.$ ai hm $\left.{ }^{-2}\right)$. For data from 2018, UAV-1, UAV-1*, KS-1 represent UAV application of isoproturon + mesosulfuron + florasulam $\left(120+0.9+0.7 \mathrm{~g}\right.$ ai $\left.\mathrm{hm}^{-2}\right)$ with 15 and $22.5 \mathrm{~L} \mathrm{ha}^{-1}$ spray volume, and knapsack sprayer application. UAV-2, UAV-2*, KS-2 represent UAV application of pinoxaden + clodinafop-propargyl + florasulam $\left(7.5+7.5+1 \mathrm{~g}\right.$ ai hm$\left.^{-2}\right)$ with 15 and $22.5 \mathrm{~L}^{-2}$ spray volume, and knapsack sprayer application. UAV-3, UAV-3*, KS-3 represent UAV application of flucarbazone-sodium + clodinafop-propargyl + mesosulfuron + florasulam $\left(3.2+7.5+0.9+1 \mathrm{~g}\right.$ ai hm $\left.{ }^{-2}\right)$ with 15 and $22.5 \mathrm{~L} \mathrm{hm}^{-2}$ spray volume, and knapsack sprayer application. Vertical bars represent standard error. Means with the same letter within the same field (2018 and 2019) and weed species (2019) are not significantly different, according to Student-Newman-Keuls ( $\alpha=0.05)$.

Figure 5 Response of major species weeds (showed as \% injury) to POST herbicides applied with different equipment and different spray volume 14 days after treatment (DAT)

In 2019, Japanese foxtail was the major weed species on field A. Bluegrass (Poa annua L.) and bedstraw was the major weed species on field B. In general, spray volume of 15 and $22.5 \mathrm{~L} / \mathrm{hm}^{2}$ did not affect weed control effect significantly. Except for bluegrass treated with flucarbazone-sodium + clodinafop-propargyl + mesosulfuron + florasulam and bedstraw treated with pinoxaden + clodinafop-propargyl + florasulam, in which low spray volume showed better effect on bluegrass and high spray volume showed better effect on bedstraw (Figure 5). Knapsack sprayer treatments showed better effect than UAV treatments on Japanese foxtail. Knapsack sprayer treatments induced 56\%-64\% injury while UAV treatments caused $20 \%-40 \%$ injury to Japanese foxtail. While for bluegrass, UAV treatments showed similar weed control effect with knapsack sprayer for isoproturon + mesosulfuron + florasulam (48\%-60\% injury). Knapsack sprayer induced less injury (25\%) than UAV applied pinoxaden + clodinafop-propargyl + florasulam (38\%-48\%), while caused more injury (34\%) than UAV of $22.5 \mathrm{~L} / \mathrm{hm}^{2}$ spray volume (12\%) for flucarbazone-sodium + clodinafop-propargyl + mesosulfuron + florasulam. For bedstraw, UAV application and knapsack sprayer showed similar effect for isoproturon + mesosulfuron + florasulam (46\%-52\%) and flucarbazone-sodium + clodinafop-propargyl + mesosulfuron + florasulam (34\%-52\%), while UAV application with $15 \mathrm{~L} / \mathrm{hm}^{2}$ spray volume showed less effect (22\%) than $22.5 \mathrm{~L} / \mathrm{hm}^{2}$ and knapsack sprayer (48\%-56\%). There was no significant difference for weed management effect among herbicide combination, except for flucarbazone-sodium + clodinafoppropargyl + mesosulfuron + florasulam that showed relatively less control effect on bluegrass.

In general, weed management efficacy of POST application in this study is unsatisfactory. Low rate herbicide showed less efficacy than high rate in 2018, which indicates weeds in this area already developed certain resistance. High rate isoproturon + clodinafop-propargyl + mesosulfuron sprayed with UAV showed similar efficacy with knapsack sprayer. This denotes that POST application with low spray volume is possible. However, in 2019, none of the herbicides applied with UAV showed better efficacy than knapsack sprayer, which indicates that low spray volume, low droplet density and weak penetrability that are associated with UAV will affect weed control efficacy of those herbicides significantly on Japanese foxtail or possibly for other grass weed. But it is not necessarily impact the effect on broadleaf weed. Spray volume is related to droplet coverage ${ }^{[27]}$ and concentrations. For some herbicides, high concentration will help absorption ${ }^{[28,29]}$ 
while some may induce necrosis and prevent absorption.

\section{Conclusions}

We explored the possibility of UAV application for PRE and POST herbicides. DJI MG-1S and 1P equipped with XR1101VS nozzles were tested in this study for both PRE and POST applications. PRE treatments tested two herbicide combinations, two application time (5 or 20 days after sowing), two herbicide rate. POST application included two herbicides combinations and two rate in 2018 , three herbicide combinations with two spray volume in 2019. When following the guideline of precautions for application. UAV application of PRE herbicides used in this study is safe to wheat seeds and seedlings. POST application via UAV with isoproturon + clodinafop-propargyl + mesosulfuron induced 10\%-20\% injury (whole plant chlorosis) that recovered 20 DAT. Other POST herbicides applied with UAV did not induce injury. Therefore, when applying herbicide combination contains mesosulfuron via UAV, operators should be more careful and test the formula in small plot before conducting large-scale application. If herbicides were resprayed with UAV (hovering above the same area when spraying), severe injury to wheat will be induced and this should be avoided. In conclusion, UAV application of herbicides on wheat is relatively safe. All PRE and POST herbicides applied by UAV and knapsack sprayer showed significant effects on weed management compared to CK. However, the effect was not uniform. In general, PRE application via UAV can achieve a great weed management (98\%) when the soil's moisture is high, has relatively smooth surface and is not covered with straw. The PRE weed control efficacy is closely related to soil management. Weeds in experimental area showed certain level of resistance for POST herbicides used in this study. UAV application of isoproturon + clodinafop-propargyl + mesosulfuron showed similar weed control efficacy with knapsack sprayer. For other herbicides, Knapsack sprayer treatments showed better effect than UAV treatments on Japanese foxtail. While for bluegrass and bedstraw, UAV treatments showed similar weed control effect with knapsack sprayer. In general, spray volume of 15 and $22.5 \mathrm{~L} / \mathrm{hm}^{2}$ did not affect weed control effect significantly. POST application with low spray volume is possible, but in some situation, low spray volume, low droplet density and weak penetrability that are associated with UAV will affect weed control efficacy.

\section{Acknowledgments}

We appreciate the technical and experimental help of Shenzhen Yuyan Intelligent Technology Services Co. Ltd., and Shenzhen Noposion Agrochemicals Co. Ltd. We appreciate the experimental instruction of the National Center for International Collaboration Research on Precision Agricultural Aviation Pesticides Spraying Technology (NPAAC). This research was funded by Shenzhen Yuyan Intelligent Technology Services Co. Ltd., and the 111 Project (D18019).

\section{[References]}

[1] Zohary D, Hopf M. Domestication of plants in the old world. Oxford University Press, Oxford, 2000.

[2] Gustafson P, Raskina O, Ma X, et al. Wheat evolution, domestication, and improvement. In: Carver B F (Ed.), Wheat: science and trade. Wiley, Danvers, 2009. pp. 5-30.

[3] Peng J, Sun D, Nevo E. Domestication evolution, genetics and genomics in wheat. Molecular Breeding, 2011; 28(3): 281-301. doi: 10.1007/s11032-011-9608-4.

[4] Lutz W, Kc S. Dimensions of global population projections: what do we know about future population trends and structures?. Philosophical Transactions of the Royal Society B: Biological Sciences, 2010; 365(1554) 2779-2791. doi: 10.1098/rstb.2010.0133.

[5] Glass C, Walters K, Gaskell P, et al. Recent advances in computational fluid dynamics relevant to the modelling of pesticide flow on leaf surfaces. Pest Management Science, 2010; 66(1): 2-9. doi: 10.1002/ps.1824.

[6] Oerke E C. Crop losses to pests. Journal of Agricultural Science, 2006; 144: 31-43.

[7] Li Y, Li Y, Pan X, et al. Comparison of a new air - assisted sprayer and two conventional sprayers in terms of deposition, loss to the soil and residue of azoxystrobin and tebuconazole applied to sunlit greenhouse tomato and field cucumber. Pest Management Science, 2017; 74(2): 448-455. doi: 10.1002/ps.4728.

[8] Rincón V J, Sánchez-Hermosilla J, Páez F, et al. Assessment of the influence of working pressure and application rate on pesticide spray application with a hand-held spray gun on greenhouse pepper crops. Crop Protection, 2017; 96: 7-13.

[9] Lan Y, Chen S, Fritz B. Current status and future trends of precision agricultural aviation technologies. International Journal of Agricultural and Biological Engineering, 2017; 10(3): 1-17. doi: 10.3965/ j.ijabe.20171003.3088.

[10] Wang G, Lan Y, Qi H, et al. Field evaluation of an unmanned aerial vehicle (UAV) sprayer: effect of spray volume on deposition and the control of pests and disease in wheat. Pest Management Science, 2019; 75(6): 1546-1555. doi: 10.1002/ps.5321.

[11] Lan Y, Thomson S J, Huang Y, et al. Current status and future directions of precision aerial application for site-specific crop management in the USA. Computers and electronics in agriculture, 2010; 74(1): 34-38. doi: 10.1016/j.compag.2010.07.001.

[12] Xue X, Liang J, Fu X. Prospect of aviation plant protection in China. Chinese Agricultural Mechanization, 2008; 5: 72-74.

[13] Xue X, Lan Y. Agricultural aviation applications in USA. Nongye Jixie Xuebao $=$ Transactions of the Chinese Society for Agricultural Machinery, 2013; 44(5): 194-201. doi: 10.6041/j.issn.1000-1298.2013.05.034.

[14] Bae Y, Koo Y M. Flight attitudes and spray patterns of a roll-balanced agricultural unmanned helicopter. Applied Engineering in Agriculture, 2013; 29(5): 675-682. doi: 10.13031/aea.29.10059.

[15] Wang M, Jin H. Spray-Induced Gene Silencing: a Powerful Innovative Strategy for Crop Protection. Trends in Microbiology, 2017; 25(1): 4-6. doi: 10.1016/j.tim.2016.11.011.

[16] Qin W C, Qiu B J, Xue X Y, et al. Droplet deposition and control effect of insecticides sprayed with an unmanned aerial vehicle against plant hoppers. Crop Protection, 2016; 85: 79-88. doi: 10.1016/ j.cropro.2016.03.018.

[17] Xue X, Qin W, Sun Z, et al. Effects of N-3 UAV spraying methods on the efficiency of insecticides against planthoppers and Cnaphalocrocis medinalis. Acta Phytophylacica Sinica, 2013; 40(3): 273-278.

[18] Menechini W, Maggi M F, Jadoski S O, et al. Aerial and ground application of fungicide in corn second crop on diseases control. Engenharia Agrícola, 2017; 37(1): 116-127. doi: 10.1590/ 1809-4430-eng.agric.v37n1p116-127/2017.

[19] Kieloch R, Domaradzki K. The influence of selected spraying parameters on two formulation of sulfonylurea herbicides effect. Journal of Central European Agriculture, 2013; 14(1): 42-51. doi: 10.5513/ JCEA01/14.1.1153.

[20] Meyer C J, Norsworthy J K, Kruger G R, et al. Effect of nozzle selection and spray volume on droplet size and efficacy of Engenia tank-mix combinations. Weed Technology, 2016; 30(2): 377-390. doi: 10.1614/ WT-D-15-00141.1

[21] [21] Ramsdale B K, Messersmith C G, Nalewaja J D. Spray volume, formulation, ammonium sulfate, and nozzle effects on glyphosate efficacy. Weed Technology, 2003; 17(3): 589-598. doi: 10.2307/3989196.

[22] Gauvrit C, Lamrani-Lucotte T, Gaudry C. Influence of application volume on herbicide efficacy. Communications in Agricultural and Applied Biological Sciences, 2003; 68(4 Pt A): 353-359.

[23] Singh S, Singh M, Dean S W. Suitable adjuvant to maximize trifloxysulfuron efficacy and early assessment of herbicide efficacy using chlorophyll fluorescence. Journal of Astm International, 2006; 1(1470): 103.

[24] Mcmullan P M. Grass herbicide efficacy as influenced by adjuvant, spray solution pH, and ultraviolet light. Weed Technology, 1996; 10(1): 72-77. 
[25] Lundkvist, A. Influence of weather on the efficacy of dichlorprop cc /mcpa and trihenuron-ethyl. Weed Research, 2008; 37(5): 361-371. doi: 10.1046/j.1365-3180.1997.d01-58.x.

[26] Somerville G J, Powles S B, Walsh M J, et al. Why was resistance to shorter-acting pre-mergence herbicides slower to evolve?. Pest Management Science, 2017; 73(5): 844-851.

[27] Antuniassi U R, Baio F H. Tecnologia de aplicação de defensivos.
Boletim de Pesquisa de Soja, 2004; 8: 165-177.

[28] Wang C J, Liu Z Q. Foliar uptake of pesticides-Present status and future challenge. Pesticide Biochemistry and Physiology, 2007; 87(1): 1-8. doi: 10.1016/j.pestbp.2006.04.004.

[29] Liu Z Q. Characterisation of glyphosate uptake into grass species. Australian Journal of Agricultural Research, 2003; 54(9): 877-884. doi: 10.1071/AR03063. 